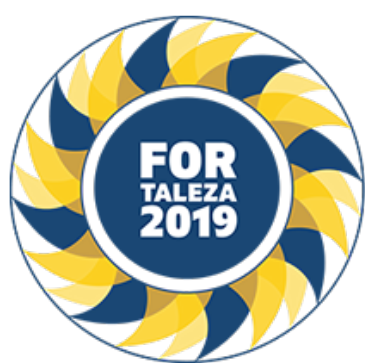

\title{
EPIDEMIOLOGICAL PROFILE OF PATIENTS USING IMMUNOBIOLOGICAL THERAPY ASSISTED IN PRIVATE
} CLINIC OF SALVADOR-BA.

Rafaela Amoedo Cox (UNIFACS, Salvador, BA, Brasil), Mauricio Matheus Benigno Barreira (UNIFACS, Salvador, BA, Brasil), Manuela Amoedo Cox (UNIFACS, Salvador, BA, Brasil), Maicon de Almeida Oliveira (UNIFACS, Salvador, BA, Brasil), Ana Teresa Amoedo (UEFS, Feira de Santana, BA, Brasil), Alexandre Ibrahim (UNIFACS, Salvador, BA, Brasil)

\section{BACKGROUND}

Assisted Immunobiological Therapy (AIT) consists of an innovation in molecular biology. It is a parenteral drug that acts at specific sites, blocking the cytokines or their receptors in the immunological or inflammatory pathways. For this reason, it is used for the treatment of autoimmune inflammatory diseases such as Ankylosing Spondylitis, Rheumatoid Arthritis, Psoriatic Arthritis, Systemic Lupus Erythematosus and Crohn's Disease.

\section{MATERIALS AND METHODS}

This is a cross-sectional study based on the collection of data from the medical records of patients submitted to immunobiological therapy in a private clinic in Salvador, Bahia, in the year 2018. All patients using this therapy in the private clinic will be included and excluded underage patients and all those who have not signed the Informed Consent Term (TCLE).

\section{RESULTS}

In the present study, data were collected from 125 patients, of these $62 \%$ female and $38 \%$ male. In this group of patients, the most prevalent age group was between 40 and 49 years corresponding to $23 \%$ of the studied population. In general data on the underlying disease, it was found that the most prevalent is Ankylosing Spondylitis with $45 \%$. In addition, it was possible to identify that $63 \%$ of patients were using the first immunobiological drug, while the most used medication in the clinic was the Infliximabe by $44 \%$ of the patients. Regarding the Medical Background, it can be said that the prevalence of patients with allergies, previous surgery and immunization were, respectively, 33\%, $74 \%$ and $88 \%$. Thinking about the women in the study, about $62 \%$ of them had been pregnant before. Regarding the patients' life habits, there was a prevalence of non-smokers and non-smokers with $74 \%$. Finally, the comorbidities of the patients were evaluated; about $40 \%$ of the patients did not have comorbidities, while those who had presented the prevalence of Systemic Arterial Hypertension (SAH) in 47 patients.

\section{CONCLUSION}

The present study determined the predominance of the female gender, non-elderly adults, immunized, submitted to previous surgery, non-smokers and non-smokers. For the most part, they are carriers of Ankylosing Spondylitis, underlying disease responsible for AIT use, and carriers of SAH, major comorbidity. The predominance of the use of Infliximab by this population is emphasized, as well as the predominance of patients using their first biological medication. 